\title{
Presenting an Innovation Model in Orange Technology
}

\author{
Babak Ziyae \\ Faculty of Entrepreneurship, University of Tehran, Tehran, Iran \\ Email: babak.ziyae@gmail.com
}

How to cite this paper: Ziyae, B. (2016) Presenting an Innovation Model in Orange Technology. Journal of Service Science and Management, 9, 433-442. http://dx.doi.org/10.4236/jssm.2016.95047

Received: July 10, 2016

Accepted: October 16, 2016

Published: October 19, 2016

Copyright $\odot 2016$ by author and Scientific Research Publishing Inc. This work is licensed under the Creative Commons Attribution International License (CC BY 4.0).

http://creativecommons.org/licenses/by/4.0/

\begin{abstract}
Nowadays, the technology is considered as a vital device to help people for consuming time, improving health, happiness and care. The path from green to orange is not only a shift learnt from green technology, but a cohesive image on the determination of technology to human civilization. Orange technology is regarded as an engine of renewal, the cross-disciplinary incorporation of humanities and technology, and the social working of promoting people care, happiness and health. The purpose of this paper is to introduce orange technology as a strategy for technology expansion in the field of improving of human's life. Since orange technology is ground-breaking and new concept in the field of entrepreneurship, the current study presents an innovative approach that could be considered in the business arena.
\end{abstract}

\section{Keywords}

Innovation, Orange Technology, Green Technology, Happiness, Health, Care

\section{Introduction}

Nowadays, technology is considered as tools to assist people for pursuing happiness and achieving value. Suggesting the green to orange is not only a rising movement learnt from green technology, but an integrated reflection on the purpose of technology to human civilization, particularly about the conflict between civilization and living after industrial revolution. How to protect and tolerate the living environment of human in order to follow a healthy and happy living is keeping green and orange at the same pace. Moreover, orange technology should be developed other than the present green technology [1].

The idea of Orange Technology was first suggested by Professor Jhing-Fa Wang, at the Department of Electrical Engineering, National Cheng Kung University, Taiwan, 
2009 [2]. It calls on worldwide scientists, economists, psychologist, sociologist, engineers, and all the other experts to dedicate their attention to such a movement, from green movement to orange movement [3]. Orange movement not only underlines the importance of the research on humanistic technologies, but also brings more health, happiness, and care to human beings [4].

The industrial revolution has caused a substantial consequence on human lifestyles. A number of changes occurred with the rapid growth of the economy and technology, including the information revolution, the second industrial revolution, and biotechnology development. Although such evolution was significantly advantageous to humans, it has caused a number of problems, such as capitalism, poverty gap, global warming, and an elderly population [3]. Because of recent changes, a number of people recognized these disasters and interested for operative answers, for example, the green movement, which successfully creates awareness of environmental protection and leads to the development of green technology or green computing [5]. However, the green movement does not focus on body and mind balance. Therefore, a solution that is possible for restriction the inconsistency between technology and humanity is of greatest concern.

In 1972, the King of Bhutan proposed a new idea that used Gross National Happiness (GNH) [6] to describe the standard of living of a country, instead of using Gross Domestic Product (GDP). The GNH has attracted significant consideration because it measured the mental health of people. Similar ideas were also proposed in other works [6]. For example, Andrew Oswald advocated Happiness Economics by combining economics with other research fields, such as psychology and sociology [7]. Moreover, a book entitled "Well-Being", which was written by Daniel Kahneman (a Nobel Prize winner in Economic Sciences in 2002) explained the basics of happy psychology [8]. The common objective of those theories is to promote the living quality of humans, and to bring more happiness into our daily lives [9].

Recently, the IEEE launched the Humanitarian Technology Challenge (HTC) project by supporting resource-constrained areas to shape reliable electricity and medical facilities [10]. Such an action also highlights the importance of humanistic care [7]. Like the HTC project, Intel has supported a Center for Aging Services Technologies (CAST), and its objective is to quicken development of innovative healthcare technologies [11]. Several academic institutes responded to the trend and then initiated medical care research, such as the "Code Blue" and "Mercury" projects at Harvard University and "Computers in the Human Interaction Loop" (CHIL) at Carnegie Mellon University [11]. Recent surveys on global healthcare markets and aging population also revealed the same phenomenon. In response to the world trend [12] and inspired by those related concepts, Professor Wang created a new interdisciplinary "Orange Technology" for studying and endorsing health, happiness, and humanistic [2].

\section{Literature Review}

Orange Technology is a new idea proposed by Dr Jhing-Fa Wang [10] which shows all 
technologies related to human health, happiness and care [8]. It embraces, but not limits to, sensors, communications, control and various software technologies. Thus, strictly speaking, Orange Technology is not a new technology but a stylish combination of existing technologies for new products/applications [13] [14].

The purpose of orange technology is to endure working the fundamental value of humanism technology [6]. To be specific, the mission of it is disadvantages could practice social caring more actively through technology, in order to pursue the value of happiness together [1]. Orange technology is the engine of new resurgence, the crossdisciplinary integration of humanities and technology, and the social functioning of promoting people's happiness and health that encourages caring to each other (Figure 1) [1] [15].

The vital goal is to make human feel blessed, which usually needs interdisciplinary partnership [16]. However, as care is one of the three aims of the Orange Technology, it is easily to associate the Orange Technology with susceptible groups such as elders, children and disabled people [16] [17].

Orange technology is a newly emerged interdisciplinary research area for combination and innovation of health, happiness, and care technologies. The research scope includes computer science, electrical engineering, biomedical engineering, psychologi$\mathrm{cal} /$ physiological science, cognitive science, and social science [4]. The illustrative color of orange technology originates from a choral fusion of red (representing brightness of health and happiness) and yellow (representing warming care). Instead of emphasizing the relations between environments and humans, as proposed by green technology, the objective of orange technology is to bring more health, happiness, warming care, and more mental wellness to society [10].

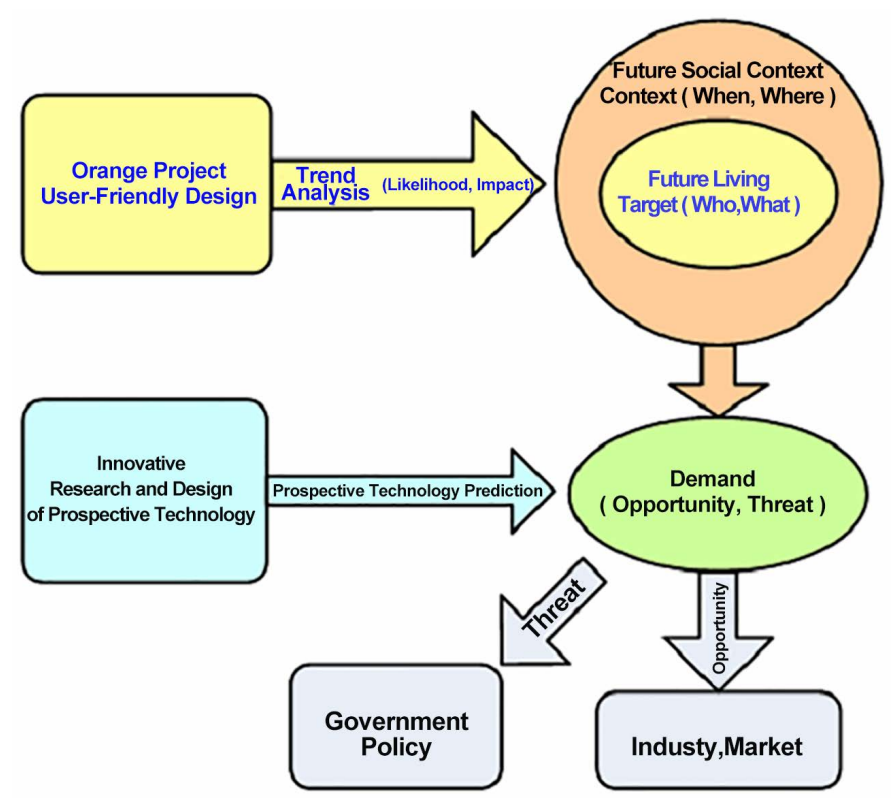

Figure 1. Orange technology is an implementing project of cross disciplinary cooperation. 


\subsection{Orange Technology and Green Technology Complement Each Other Well}

The green of green technology signifies the environment, which devotes to reduce carbon emissions and to save energy in order to progress our living environment [2]. As for the orange of orange technology that interprets humanities, the temperature of its color presents the vitality that cares about how to pursue a happy and healthy living. Therefore, from green to orange would be reflecting how the development of technology could ensure the quality of living environment more comprehensively, and also the pursuit of health and happiness. On the other hand, from green to orange would not only be the turning of the goal of technology development, but a more comprehensive starting of mission (Figure 2) [1].

The purpose of orange technology is to call for striving people's attention from all over the world on the issue of research and promotion of human technology, further allows technology to bring health, happiness and humane care to all. Not only from green to orange technology, but green to orange movement that covers: 1) health and safety care and disease prevention of elders, 2) health and safety care and disease prevention of children, 3) protection and rescue of natural disaster for victims, 4) caring for low-income households, 5) caring for physical and mental disabilities, 6) promotion of humanities accomplishment, and etc. The above could be covered to accelerate the promotion of orange technology. Orange technology could even be extended to orange economy, orange design, orange product, orange space and so on [10].

Orange technology and green technology supplement each other well. Green technology emphasizes on environmental protection, whereas orange technology highlights humanism. Through such combination of green technology and orange technology, a complete mission can be succeeded [10].

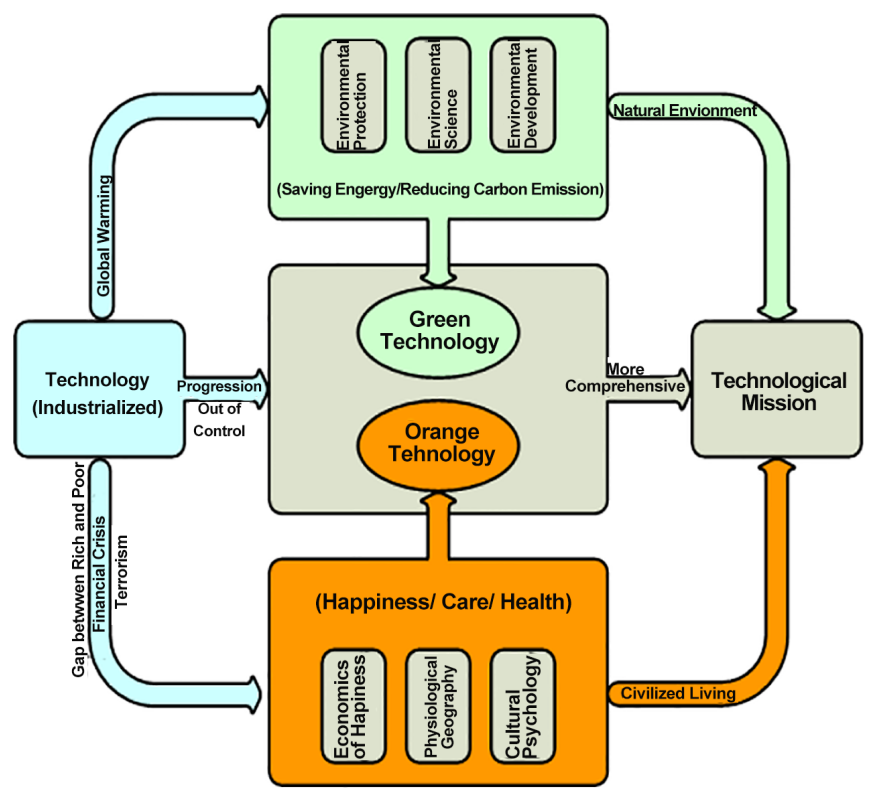

Figure 2. From green to orange. 


\subsection{Model Orange Technology}

Wang et al. [2] proposed a concept for modeling health, happiness, and warming care. As water is essential to life on earth, Health model, Happiness model, and Offering/ Caring/Warming model are abbreviated to $\mathrm{H}_{2} \mathrm{O}$, for it symbolizes the essence of body and mind:

- The health model is commonly used in medical expert systems. When a user inputs a query to the interface, the system then consults with an expert or doctor [2]. After merging the opinion of the expert into the knowledge database, the system replies the user with a proper response [10].

- Like the health model, the happiness model also needs a user input and a predefined database. Most of time, the input is measured from the biosignals or behavior of a user, e.g., blood pressure, heart rates, gaits, laughter, etc. Thus, how to combine those data and determine happiness status becomes a challenging task [2].

- The Offering/Caring/Warming (OCW) model plays a key role in Orange Technology since it involves whom, how, and when to give proper feedback. It also requires accurate semantic understanding techniques and delicate Human-Computer Interactions (HCIs) [2].

Orange Index: Like Carbon footprints used in green technology, Orange Technology also adopts a criterion for calculating the degree of health, happiness, and warming care. Such an index can be used to evaluate a theory, a product, and even a policy [9]. Based on the theory of Wang et al. [2] orange index is discussed from the three aspects: magnitude, spectrum, and continuance.

- Magnitude measures the strength of a model. When tested on humans, it can be regarded as how strong a person feels.

- Spectrum refers to the range and the spread of a model. It discussed about how large population a model can cover, e.g., products, persons, companies, communities, and nations.

- Continuance evaluates the duration of the model and how long it takes effects on subjects.

Besides, orange index can be further decomposed into three sub-indices: health, happiness, and care. The following content introduces examples of each indicator (Figure 3).

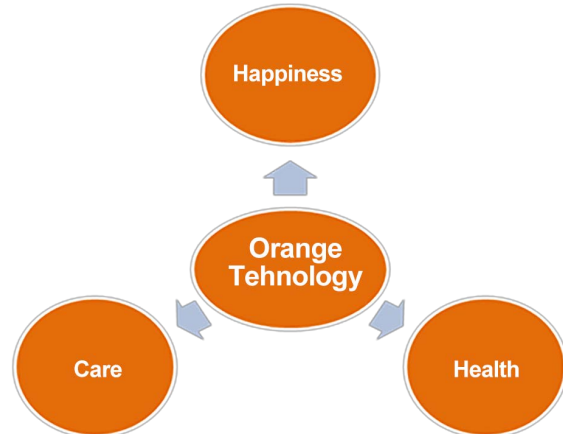

Figure 3. Three orange technology subindices. 
A) Happiness index:

- For nations: Prozac index can be viewed as a kind of happiness degrees since Prozac has been widely used in treatment of depression for many years. The idea of Prozac index is analogous to Fine Wine Index proposed by Liv-Ex. It calculates the entire consumption of a nation in a year. When the consumption grows, it represents unhappiness level increases [2].

- For persons or products: Happiness tracks, or namely happiness degrees. In 2012, Wang et al. [2] proposed that personal happiness can be estimated by using laughter and smiles in a day. The electrical sensors were used to recognize and log the number of laughter and smiles generated by a person. In fact, personal emotions can be used for measurement of products. When tastes are using products, happiness footprints, e.g., Dopamine, are measured via their experience by sensors, equipments, or simply questionnaires.

B) Health index:

- For nations: such an indicator has been broadly investigated for many decades. For example, Global Health Observatory (GHO) of World Health Organization (WHO) publishes world health statistics reports annually [10]. Their indicators include alcohol consumption, fertility rates, mortality rates, general government expenditure on health, and infection rates of specific diseases [18].

- For persons or products: Indices include toxic ingredients in products or substances secreted by human bodies [2].

C) Care index:

- For nations: This topic involves social care and community harmony. Charity donation, social worker population, retirement house coverage, etc. can be selected as care indices.

- Orange Transform: Any non-orange production or design can be converted into orange one as long as it adds three orange factors, including happiness index, health index, and care index, into the process or itself. Furthermore, all the indices need to be higher than a predefined threshold [8].

\subsection{New innovation in Orange Technology}

In 2010, the new innovation model included "Orange Technology" in the theme. Through this program it made people know more about the trend from Green Technology to Orange Technology [11]. Because of caring of the earth and the elder are all important issues, the second of "Promoting Program for cross-field creative scenario value-adding" prototype exhibition found that many specialist are interested in this Orange Design issue [13]. These creative ideas from different domains are humanism, management, engineering, bio-techs [7]. There were 104 out of 181 designs used Orange Technology and 30 orange designs had executable potential [7]. Among the interdisciplinary teams, 14 projects made actual technology feasibility evaluation, the final 9 projects finished prototyping [7]. These works are as follows: Beep System an reasonable alarm device for wheelchair users; self-powered digital lung capacity tester; brain 
computer interface-based music player with the function of music therapy for people with dementia; Design and Implementation of drug/food/ vegetarian ingredients reminding system based on integration of barcode recognition, cloud computing and family speech synthesis; automated-alert helmet; personal mobile device with crossing over obstacles wheels; adjustable hydrotherapy floatation jacket; system of interactive sound and light for eye-hand coordination training Groups of passion researchers are devoting themselves in orange technology and orange design [1]. They form a close community on the open platform of interdisciplinary creative value-adding and they corporate each other to make the Orange Dream come true [13] [19].

\subsection{Technology Development Policy}

First ever world happiness report has been published recently by the United Nations, which reflects a new global demand for more attention to happiness as criteria for management policy [13] [20]. This also calls upon science and technology in both natural and social areas to be developed for endorsing a happy and healthy lifestyle in our modern society [4] [14]. To respond to such a trend, the research center of National Chung Kung University at Taiwan proposes a new concept orange computing [9] for health, happiness, and humanistic care. Rather than emphasizing the relations between environments and humans as green technology does, orange computing focuses on designing procedures and systems for enhancing body and mind balance [13]. The goal of orange computing is to bring more care or happiness to humans, and finally to promote the well-being of society [5] [17]. The research center also launches a three-year interdisciplinary project studying health, happiness, and care technologies. The research scope includes computer science, electrical engineering, biomedical engineering, psychological/physiological science, cognitive science, and social science [12] [15].

Figure 4 shows the overview of the project. It is composed of the following seven subprojects:

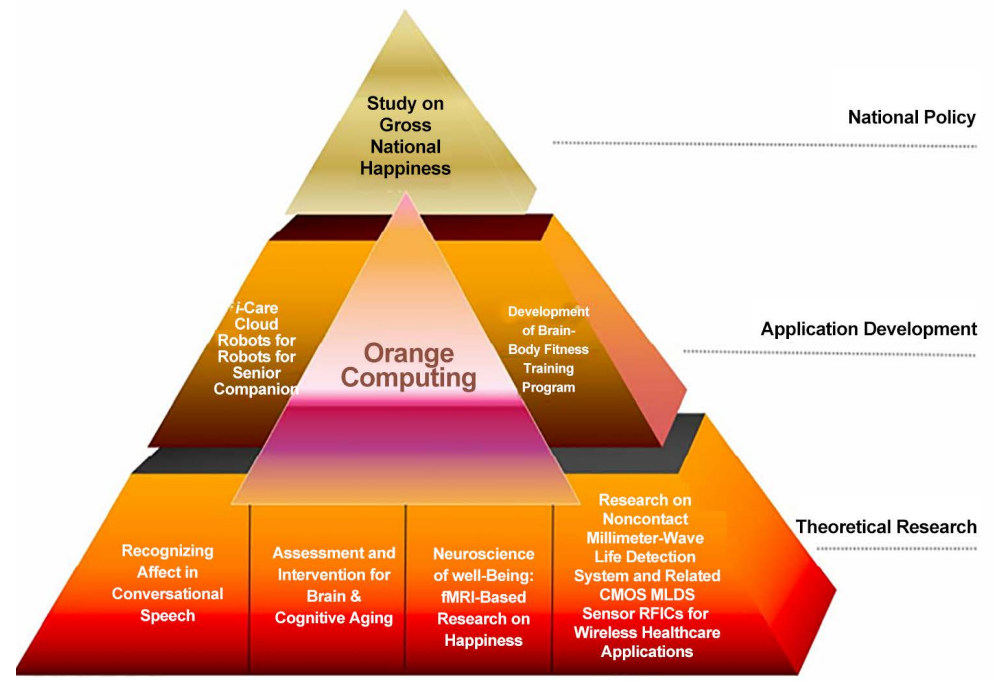

Figure 4. Project overview. 
Subproject 1: $i$-Care Cloud Robots for Senior Companion.

Subproject 2: Study of Gross National Happiness.

Subproject 3: Development of Brain-Body Fitness Training Program.

Subproject 4: Recognizing Affection in Conversational Speech.

Subproject 5: Research on Noncontact Millimeter-Wave Life Detection System and Related.

Subproject 6: Assessment and Intervention for Brain and Cognitive Aging.

Subproject 7: Neuroscience of Well-Being: fMRI-Based Research on Happiness.

Additionally, these subprojects can be classified into three layers according to their subjects, where the bottom layer is theoretical research, the middle layer is application development, and the top layer is related to national policy. All the subprojects are surrounded by the central concept "orange computing." The project is expected to realize the research results in practical applications and the nation policy level [2] [16].

Regarding the research fields of Orange Technology, it includes the studies on 1) health technology, 2) happiness technology, and 3) warm technology. The detailed research fields may include:

1) Healthcare and disease treatment for the elderly.

2) Healthcare and disease treatment for children.

3) Care and disaster relief for stricken areas.

4) Care for low-income families.

5) Care for those with the problems of physiology, psychology, and spirits (i.e., body and mind care).

Orange Technology can even be extended to other areas, such as Orange Economy, Orange Design, Orange Product, and Orange Space, Orange Service, to bring more health, happiness, and warm care to human being [18] [21].

\section{Conclusions}

Technology is regarded as tools to serve people for pursuing happiness and fulfilling value. Orange Technology is a novel concept which indicates all technologies related to human health, happiness and care. The intention of orange technology is to continue practicing the fundamental value of humanism technology to be specific. The mission of it is that disadvantages could practice social caring more actively through technology, in order to pursue the value of happiness together. The ultimate goal is to make human feel blessed, which usually needs interdisciplinary collaboration. The green of green technology represents the environment, which dedicates to reduce carbon emissions and to save energy in order to improve our living environment. As for the orange of orange technology that interprets humanities, the temperature of its color presents the vitality that cares about how to pursue a happy and healthy living. Therefore, from green to orange would be reflecting how the development of technology could ensure the quality of living environment more comprehensively, and also the pursuit of health and happiness.

Orange technology in government policy could lead to the development of a tech- 
nological innovation system. This innovation in the areas of health, happiness and care and with an interdisciplinary approach to the development of research in science and new businesses will be created. The research scope includes computer science, electrical engineering, biomedical engineering, psychological/physiological science, cognitive science, and social science Interdisciplinary research in the sciences through established specialized structures to support commercialization, such as technology transfer offices (TTOs), science parks and incubators, expand research projects universities to innovation. Orange Technology Research fields include: 1) healthcare and disease treatment for the elderly, 2) healthcare and disease treatment for children, 3) care and disaster relief , 4) care for low-income families, 5) care for those with the problems of physiology, psychology, and spirits (i.e., body and mind care), and 6) computer games.

However, mental care has become vital with the rapid growth of economy and technology. Recent actions, such as green technologies, place more stress on environmental issues than on mental care. Therefore, this study presents an emerging technology called orange technology. Orange technology refers to health, happiness, and physio psychological care computing, which focuses on designing algorithms and systems for enhancing body and mind equilibrium. The representative color of Orange technology originates from a harmonic fusion of passion, love, happiness, and warmth. The system can notice emotional states of people by analyzing their facial expressions, emotional speech, and happiness in a pervasive environment. In addition, the system can provide corresponding feedback to users according to the results. Future experimental studies can reveal that the systems can achieve an accurate audiovisual recognition rate, thereby demonstrating the feasibility of the system.

Assimilating study from different fields can increase its capacity to expand strategies and rich social context. More qualitative research with grounded theory helps to create innovate business and improve health models. Considering any research or implementation approach in isolation misses the significant advantage of addressing them together. Current mechanisms of assessing health or funding research too often ignore a broad system wide approach.

\section{References}

[1] Gilk, L. (2009) Green Politics Is Eutopian. Lutterworth Press, Cambridge.

[2] OECD Health Data (2012) Paris Cedex, France: Organisation for Economic Co-Operation and Development. 198-203.

[3] Chen, S.-H. and Lee, R.S. (2013) A New Innovation Model: Interdisciplinary Creative Value-Adding toward Commercialization. 2013 International Conference on Orange Technologies (ICOT), 12-16 March 2013, 164-467.

[4] Lorincz, K., Malan, D.J., Fulford-Jones, T.R.F., et al. (2004) Sensor Networks for Emergency Response: Challenges and Opportunities. IEEE Pervasive Computing, 3, 16-23. http://dx.doi.org/10.1109/MPRV.2004.18

[5] Hargens, S.B.F. (2002) Integral Development-Taking the Middle Path towards Gross National Happiness. Journal of Bhutan Studies, 6, 24-87.

[6] Chen, Y.-Y., Chen, B.-W., Wang, J.-F. and Chen, Y.-C. (2010) Emotion Aware System 
Based on Acoustic and Textual Features from Speech. Proceedings of the 2nd International Symposium on Aware Computing (ISAC10), Tainan, 1-4 November 2010, 92-96.

[7] Dunachie, F. (1996) The Success of the Industrial Revolution and the Failure of Political Revolutions: How Britain Got Lucky. Historical Notes, 8, 1-7.

[8] Liou, S. (2013) Toward a Technology for Humanity a More Comprehensive Technological Mission. 2013 International Conference on Orange Technologies (ICOT), Tehran, 75-78.

[9] Busso, C. and Narayanan, S. (2007) Interrelation between Speech and Facial Gestures in Emotional Utterances: A Single Subject Study. IEEE Transactions on Audio, Speech and Language Processing, 15, 2331-2347. http://dx.doi.org/10.1109/TASL.2007.905145

[10] Kahneman, D., Diener, E. and Schwarz, N. (2008) Well-Being: The Foundations of Hedonic Psychology. Russell Sage Foundation Publications, New York.

[11] Hargens, S.B.F. (2002) Integral Development-Taking the Middle Path towards Gross National Happiness. Journal of Bhutan Studies, 6, 24-87.

[12] Hata, Y., Kobashi, S. and Nakajima, H. (2009) Human Health Care System of Systems. IEEE Systems Journal, 3, 231-238. http://dx.doi.org/10.1109/JSYST.2009.2017389

[13] Chang, D.T.-H., Hung, Y.-H., Li, S.-C., Cheng, H.-H., Wang, H., Chou, C.-W. and Tang, Y.-C. (2013) An Orange Social Platform for Young People. 2013 International Conference on Orange Technologies (ICOT), 12-16 March 2013, 325-327. http://dx.doi.org/10.1109/ICOT.2013.6521224

[14] Wang, J-F. Chen, B., Fan, W. and Li, C. (2012) Emotion-Aware Assistive System for Humanistic Care Based on the Orange Computing Concept. Applied Computational Intelligence and Soft Computing, 2012, Article ID: 183610. http://dx.doi.org/10.1155/2012/183610

[15] Wang, H-Y., Chen, B., Bharanitharan, K., Wu, J., Tseng, S. and Wang, J. (2013) Human-Centric Technology Based on Orange Computing. 2013 International Conference on Orange Technologies (ICOT), 12-16 March 2013, 250-251. http://dx.doi.org/10.1109/ICOT.2013.6521204

[16] Wang, J.-F. and Chen, B.W. ( 2012) Orange Technology: A Power Which Changes the World. 1st Edition, Orange Technology and GNH Research and Development Center, National Cheng Kung University, Tainan.

[17] Wang, J.-F. and Chen, B.W. (2011) Orange Computing: Challenges and Opportunities for Awareness Science and Technology. International Conference of Knowledge, Tehran, 8799.

[18] Jensen,S. (2013) The Modern Industrial Revolution, Exit, and the Failure of Internal Control Systems. Journal of Applied Corporate Finance, 22, 43-58. http://dx.doi.org/10.1111/j.1745-6622.2010.00260.x

[19] Veneris, Y. (1990) Modelling the Transition from the Industrial to the Informational Revolution. Environment \& Planning, 21, 399-416. http://dx.doi.org/10.1068/a220399

[20] Waibel, A. (2008) Speech Processing in Support of Human-Human Communication. Proceedings of 2nd International Symposium of Universal Communication, Osaka, 11-21.

[21] Wang, J.-F. and Chen, B.-W. (2012) From Green Computing to Orange Computing: A Newly Defined Interdisciplinary Research Area for Integration and Innovation of Health, Happiness and Warming Care Technologies. IEEE Region 10 Newsletter: 10. 
Submit or recommend next manuscript to SCIRP and we will provide best service for you:

Accepting pre-submission inquiries through Email, Facebook, LinkedIn, Twitter, etc. A wide selection of journals (inclusive of 9 subjects, more than 200 journals)

Providing 24-hour high-quality service

User-friendly online submission system

Fair and swift peer-review system

Efficient typesetting and proofreading procedure

Display of the result of downloads and visits, as well as the number of cited articles

Maximum dissemination of your research work

Submit your manuscript at: http://papersubmission.scirp.org/

Or contact jssm@scirp.org 